\title{
COMMENTARY
}

\section{Are we sedating more than just the brain?}

\author{
Nathan E Brummel $\left.\right|^{* 1,2}$ and Timothy D Girard ${ }^{1-3}$ \\ See related research by Strøm et al., http://ccforum.com/content/15/3/R119
}

\begin{abstract}
Heavy sedation in the ICU is associated with coma, delirium, and prolonged stays, but links between sedatives and non-brain organ failure have rarely been described. In a post hoc analysis, Strøm and colleagues explored associations between sedation and acute kidney injury among ICU patients randomly assigned to one of two sedation strategies. The 'no sedation' protocol was associated with less kidney injury, but methodologic limitations preclude firm conclusions regarding mechanisms underlying this association. This hypothesis-generating study warns that sedation may harm organs other than the brain during critical illness, a possibility that warrants careful study in the future.
\end{abstract}

ICU patients are often sedated to prevent pain and anxiety and to facilitate care. Heavy sedation, however, is associated with adverse effects, including prolonged mechanical ventilation, ICU and hospital stays, and increased mortality [1-5]. Nevertheless, deep sedation is frequently used [6], exposing patients to potential shortand long-term complications, such as ICU delirium [7] and subsequent long-term cognitive impairment [8].

Although studies of ICU sedation have focused primarily on brain-related outcomes, other organ systems may be affected. Acute kidney injury (AKI) is common in the ICU and is associated with increased length of stay and in-hospital mortality [9]. In this issue of Critical Care, Strøm and colleagues [1] describe a post hoc analysis of renal outcome data among 103 mechanically ventilated ICU patients enrolled in the authors' previously published trial of 'no sedation' versus a continuous sedation strategy [5]. The authors hypothesized that sedation-induced hypotension would result in

\footnotetext{
*Correspondence: nathan.e.brummel@vanderbilt.edu

'Division of Allergy, Pulmonary, and Critical Care Medicine, Department of Medicine, Vanderbilt University School of Medicine, 1215, 21st Avenue South, Medical Center East, 6th Floor, Suite 6000, Nashville, TN 37232-8300, USA Full list of author information is available at the end of the article
}

more vasopressor use, fluid administration, and AKI among patients in the control group compared with those receiving 'no sedation'.

Patients in the 'no sedation' group were managed with morphine as needed for pain and, if necessary, short courses ( $<6$ hours) of sedation with propofol; patients in the control group received continuous propofol infusions with daily interruption. Outcomes included mean arterial pressure, use of vasopressor/inotropic drugs, fluid balance, urine output, and serum creatinine, the latter two being used to classify AKI using the RIFLE (risk, injury, failure, loss, and end-stage renal failure) criteria [10].

No difference between groups was observed in mean arterial pressure or amount of vasopressors required, but patients in the 'no sedation' group had greater average urine output during the 14-day period of analysis (1.15 versus $0.88 \mathrm{~mL} / \mathrm{kg}$ per hour), and this translated to a lower prevalence of AKI (51\% versus 76\%). The authors thus conclude that the 'no sedation' strategy results in less AKI than standard ICU sedation approaches.

Important limitations make it difficult for Strøm and colleagues to conclusively prove that sedation impairs kidney function: eligibility criteria were altered, potentially invalidating the randomization scheme; imbalances in baseline risk factors for AKI may have confounded results; and no adjustments were made for baseline kidney function. Nevertheless, this work provides us with early evidence suggesting that sedation may injure organs other than the brain. The mechanism underlying the association between sedation and renal impairment, however, remains unclear. The control group did not have more hypotension, fluid administration, or vasopressor use than the 'no sedation' group, findings that would have supported the authors' hypothesis that sedation-induced hypotension leads to worse renal perfusion. Because this small study relied on summary measures rather than taking advantage of repeated measures, statistical power to detect differences in hemodynamic outcomes may have been low. Alternatively, other mechanisms might play a role.

Patients managed with the 'no sedation' protocol, for example, spent less time on mechanical ventilation, and this could explain observed changes in urine output. Mechanical ventilation has been linked to poor renal 
function in both animal and human studies and is hypothesized to occur via several mechanisms: (a) positive intrathoracic pressure redistributes intrarenal blood flow and reduces cardiac output, causing decreased renal perfusion; (b) neurohormonal changes, including increased sympathetic outflow, release of antidiuretic hormone, and decreases in atrial natriuretic peptide, cause fluid retention and oliguria; and (c) inflammatory mediator release in response to lung injury directly injures the kidney $[11,12]$. An analysis examining the timing of AKI relative to time on the ventilator - both time-dependent variables [13] - may have yielded results supporting these possible mechanisms. Large prospective cohort studies measuring circulating inflammatory and neurohormonal markers could elucidate the roles of these potential mechanisms in the development of AKI during critical illness.

In summary, Strøm and colleagues provide an important hypothesis-generating study highlighting potential systemic effects of sedatives in the ICU and raising important questions about sedative use and organ failure. What mechanisms explain the increase in AKI associated with sedative exposure? What are the long-term consequences of sedation-associated AKI in the ICU? Are other organ systems at risk of sedative-associated injury? This study adds to the now-large body of literature warning that clinicians should be mindful of the benefits versus the harms of sedation in the ICU. More studies of optimal sedative regimens in the ICU, examining preferred agents and long-term outcomes, are needed.

\section{Abbreviations}

AKI, acute kidney injury; ICU, intensive care unit

\section{Competing interests}

The authors declare that they have no competing interests.

\section{Author details}

'Division of Allergy, Pulmonary, and Critical Care Medicine, Department of Medicine, Vanderbilt University School of Medicine, 1215, 21st Avenue South, Medical Center East, 6th Floor, Suite 6000, Nashville, TN 37232-8300, USA

${ }^{2}$ Center for Health Services Research, Vanderbilt University School of Medicine, 1215, 21st Avenue South, Medical Center East, 6th Floor, Suite 6000, Nashville, TN 37232-8300, USA. ${ }^{3}$ Geriatric Research, Education and Clinical Center (GRECC) Service, Department of Veterans Affairs Medical Center, Tennessee Valley Healthcare System, 1310, 24th Avenue South, Nashville, TN 37212-2637, USA.
Published: 7 June 2011

\section{References}

1. Strøm T, Johansen R, Prahl J, Toft P: Sedation and renal impairment in critically ill patients: a post hoc analysis of a randomized trial. Crit Care 2011, 15:R119.

2. Kollef MH, Levy NT, Ahrens TS, Schaiff R, Prentice D, Sherman G: The use of continuous i.v. sedation is associated with prolongation of mechanical ventilation. Chest 1998, 114:541-548

3. Kress JP, Pohlman AS, O'Connor MF, Hall JB: Daily interruption of sedative infusions in critically ill patients undergoing mechanical ventilation. N Engl J Med 2000, 342:1471-1477.

4. Girard TD, Kress JP, Fuchs BD, Thomason JW, Schweickert WD, Pun BT, Taichman DB, Dunn JG, Pohlman AS, Kinniry PA, Jackson JC, Canonico AE, Light RW, Shintani AK, Thompson JL, Gordon SM, Hall JB, Dittus RS, Bernard GR, Ely EW: Efficacy and safety of a paired sedation and ventilator weaning protocol for mechanically ventilated patients in intensive care (Awakening and Breathing Controlled trial): a randomised controlled trial. Lancet 2008, 371:126-134.

5. Strøm T, Martinussen T, Toft P: A protocol of no sedation for critically ill patients receiving mechanical ventilation: a randomised trial. Lancet 2010, 375:475-480.

6. Payen JF, Chanques G, Mantz J, Hercule C, Auriant I, Leguillou JL, Binhas M, Genty C, Rolland C, Bosson JL: Current practices in sedation and analgesia for mechanically ventilated critically ill patients: a prospective multicenter patient-based study. Anesthesiology 2007, 106:687-695; quiz 891-682.

7. Pandharipande P, Shintani A, Peterson J, Pun BT, Wilkinson GR, Dittus RS, Bernard GR, Ely EW: Lorazepam is an independent risk factor for transitioning to delirium in intensive care unit patients. Anesthesiology 2006, 104:21-26.

8. Girard TD, Jackson JC, Pandharipande PP, Pun BT, Thompson JL, Shintani AK, Gordon SM, Canonico AE, Dittus RS, Bernard GR, Ely EW: Delirium as a predictor of long-term cognitive impairment in survivors of critical illness. Crit Care Med 2010, 38:1513-1520.

9. Uchino S, Kellum JA, Bellomo R, Doig GS, Morimatsu H, Morgera S, Schetz M, Tan I, Bouman C, Macedo E, Gibney N, Tolwani A, Ronco C; Beginning and Ending Supportive Therapy for the Kidney (BEST Kidney) Investigators: Acute renal failure in critically ill patients: a multinational, multicenter study. JAMA 2005, 294:813-818.

10. Bellomo R, Ronco C, Kellum JA, Mehta RL, Palevsky P: Acute renal failure - definition, outcome measures, animal models, fluid therapy and information technology needs: the Second International Consensus Conference of the Acute Dialysis Quality Initiative (ADQI) Group. Crit Care 2004, 8:R204-212.

11. Pannu N, Mehta RL: Effect of mechanical ventilation on the kidney. Best Pract Res Clin Anaesthesio/ 2004, 18:189-203.

12. Koyner UL, Murray PT: Mechanical ventilation and the kidney. Blood Purif 2010, 29:52-68.

13. Shintani AK, Girard TD, Eden SK, Arbogast PG, Moons KG, Ely EW: Immortal time bias in critical care research: application of time-varying Cox regression for observational cohort studies. Crit Care Med 2009, 37:2939-2945.

doi:10.1186/cc10233

Cite this article as: Brummel NE, Girard TD: Are we sedating more than just the brain? Critical Care 2011, 15:163. 